9. Roussel TJ, Stern WH, Goodman DF, Whitcher JP Postoperative mycobacterial endophthalmitis. Am J Ophthalmol 1989;107:403-6.

10. Zimmerman PL, Mamalis N, Alder JB, Teske MP, Tamura M, Jones GR. Chronic Nocardia asteroides endophthalmitis after extracapsular cataract extraction. Arch Ophthalmol 1993;111:837-40.

11. Runyon EH. Anonymous mycobacteria in pulmonary disease. Med Clin North Am 1959;43:273-7.

12. Broadway DC, Kerr-Muir MG, Eykyn SJ, Pambakian H. Mycobacterium chelonei keratitis: a case report and review of previously reported cases. Eye 1994;8:134-42.

13. Smith RE, Salz JJ, Moors R, Silverstein D, Lewis W. Mycobacterium chelonei and orbital granuloma after tear duct probing. Am J Ophthalmol 1980;89:139-40.

14. Rootman DS, Insler MS, Wolfley DE. Canaliculitis caused by Mycobacterium chelonae after lacrimal intubation with silicone tubes. Can J Ophthalmol 1989; 24:221-2.

15. Pope J, Sternberg P, McLance NJ, Potts DW, Stulting RD. Mycobacterium chelonae scleral abscess after removal of a scleral buckle. Am J Ophthalmol 1989; 107:557-8.

16. Smiddy WE, Miller D, Flynn HW Jr. Scleral buckle infections due to atypical mycobacteria. Retina 1991; 11:394-8.

17. Ambler JS, Meisler DM, Zakov ZN, Hall GS, Spech TJ. Endogenous Mycobacterium chelonae endophthalmitis. Am J Ophthalmol 1989;108:338-9.

18. Rosenfeld SJ, Jost BF, Litinsky SM, Gelender H, Glatzer RJ, Flynn HW Jr. Persistent Torulopsis magnoliae endophthalmitis following cataract extraction. Ophthalmic Surg 1994;25:154-6.

19. Bullington RH Jr, Lanier JD, Font RL. Nontuberculous mycobacterial keratitis: report of two cases and review of the literature. Arch Ophthalmol 1992;110: 519-24.

20. Hykin PG, Tobal K, McIntyre G, Matheson MM, Towler HM, Lightman SL. The diagnosis of delayed post-operative endophthalmitis by polymerase chain reaction of bacterial DNA in vitreous samples. J Med Microbiol 1994;40:408-15.

21. Cooper JF, Lichtenstein MJ, Graham BH, Schaffner W. Mycobacterium chelonae: a cause of nodular skin lesions with a proclivity for renal transplant recipients. Am J Med 1989;86:173-9.

Sir,

\section{A Case of a Late Complication After Naso-lacrimal Duct Intubation}

Reconstruction of the lacrimal passages in chronic dacryocystitis can be achieved by several surgical techniques, although dacryocystorhinostomy is the most successful operation. ${ }^{1}$ Dacryocystorhinostomy is not an easy surgical procedure and gives good results only in competent hands. ${ }^{1}$

Intubation of the naso-lacrimal duct is another surgical procedure but results after this technique are somewhat poor and variable; various workers ${ }^{2-4}$ have tried intubation of the naso-lacrimal duct with a success rate of up to $93 \%$. Stallard and others ${ }^{2,5,6}$ have, however, reported poor results. Since 1944, plastic tubing has been used to restore patency of the

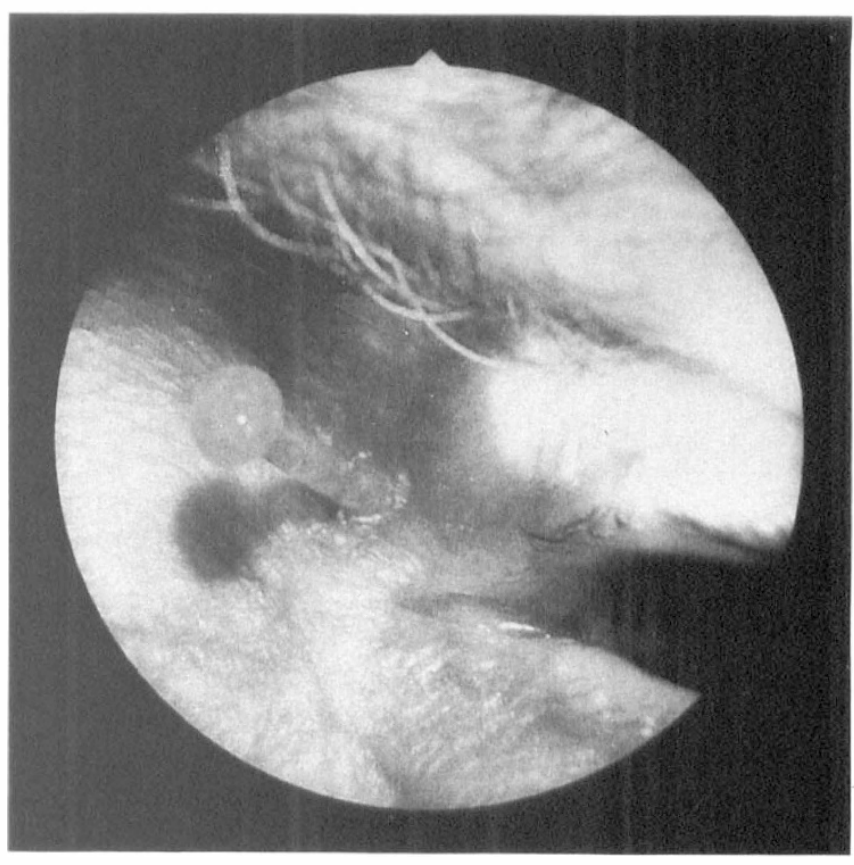

Fig. 1. An 87-year-old woman presenting with a nasolacrimal duct tube eroding through the skin above the left medial palpebral ligament.

lacrimal passages, with no evidence of tissue intolerance, ${ }^{4}$ whereas the use of metallic tubes was abandoned because of the risk of foreign body reaction, varying from mild inflammation to necrosis. $^{7}$

The clinical case presented is a late complication of naso-lacrimal duct intubation, in which a polyethylene tube was expelled 4 years after surgery.

\section{Case Report}

An 87-year-old woman attended the casualty unit in November 1992 with a polyethylene tube, placed for naso-lacrimal duct intubation, presenting through the skin just above the left medial palpebral ligament (Fig. 1). For 3 months prior to attendance she had been aware of a painless lump under the skin of her left upper lid.

The tube, extending for $14 \mathrm{~mm}$ out of the skin, was $29 \mathrm{~mm}$ long and had a diameter of $2 \mathrm{~mm}$ with a flange of $4 \mathrm{~mm}$ (Fig. 2). The tube was obstructed by a plug of solid necrotic material and there was pus around the tube. After removal of the tube, the wound was washed with gentamicin and the site healed in 3 days.

Clinical history revealed that she had suffered from chronic dacryocystitis for a long time. She first had a naso-lacrimal duct intubation with a polyethylene tube performed in March 1984, the surgical procedure being based on the method described by Summerskill in $1952 . *^{4}$ This operation did not relieve the patient's symptoms and she continued to suffer from epiphora, visual impairment and spontaneous regurgitation from her left lacrimal puncta. In January 1988 a second naso-lacrimal duct polyethy- 


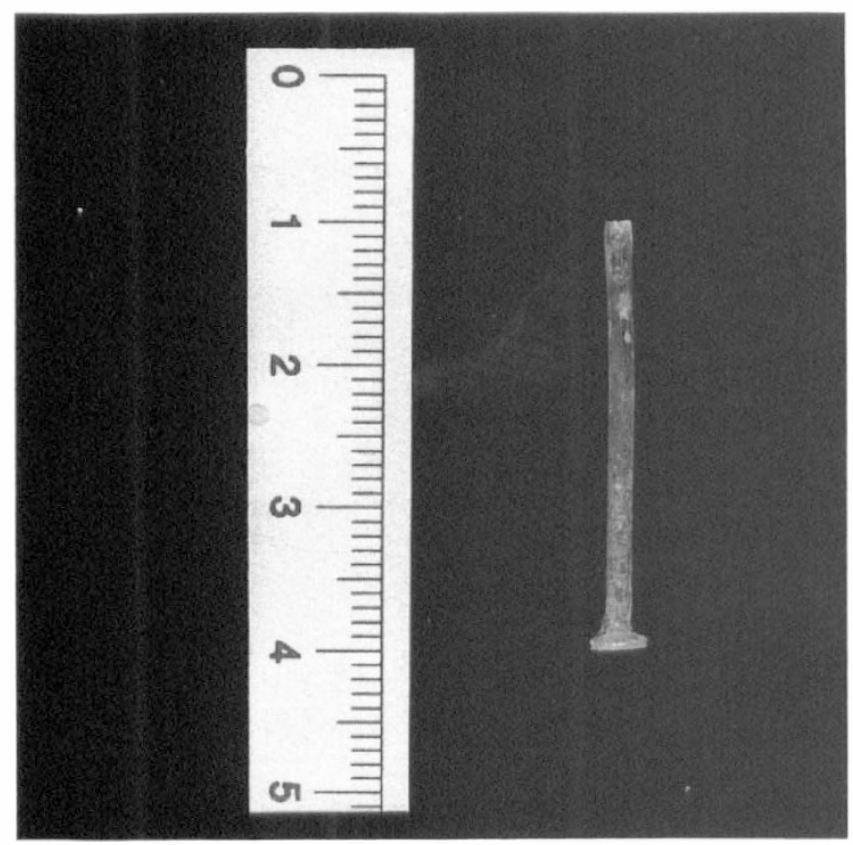

Fig. 2. The polyethylene tube, placed during Summerskill's operation 4 years prior to presentation, was $29 \mathrm{~mm}$ long and $2 \mathrm{~mm}$ diameter, with a flange of $4 \mathrm{~mm}$.

lene tube was placed by the same surgeon, using the same technique, but the symptoms persisted.

\section{Discussion}

In chronic dacryocystitis, obstruction of the lacrimal passages is generally either at the junction of the sac and the naso-lacrimal duct or lower, within the bony naso-lacrimal duct itself. ${ }^{1}$ The value of draining an infected sac into the nose was recognised 1500 years ago by surgeons of the Byzantine school, who performed a crude dacryocystorhinostomy by passing a cautery through the sac and the lacrimal bone; such an opening rapidly closed. ${ }^{4}$

In 1904 Toti laid the foundation of the modern operation of external dacryocystorhinostomy ${ }^{4}$ and $\mathrm{Ohm}$ first described the modern dacryocystorhinostomy in $1920 .^{8}$

\footnotetext{
*According to this method the incision runs from the medial palpebral ligament $3 \mathrm{~mm}$ internal to the medial canthus to the level of the upper opening of the bony canal. An incision of $8 \mathrm{~mm}$ is made through the fascia into the sac in its long axis, terminating below just above the commencement of the duct. The smallest of three probes, the largest $6 \mathrm{~mm}$ in diameter, is passed into the sac and down into the commencement of the naso-lacrimal duct. Therefore, to perforate the lacrimal bone at its lowest part, the probe is withdrawn slowly from the duct, and as its point leaves the upper end it is passed medially and slightly backwards and downwards. Little pressure is required to perforate the bone, and the probe is passed on until it touches the nasal septum. The opening is enlarged by passing the medium-sized and then the largest probe. The polyethylene tube is then inserted on the applicator (a rod $4 \mathrm{~mm}$ in diameter with a shoulder $12 \mathrm{~mm}$ from the end) and care is taken to see that it is firmly in position with the flanges in the long axis of the sac. The tube is washed through with the lacrimal syringe to free it from blood and debris, and the sac is closed by interrupted catgut sutures. The skin is closed by interrupted silk sutures and a dry dressing held by strapping is applied.
}

Summerskill (1952) later described another type of dacryocystorhinostomy by intubation of the nasolacrimal duct; ${ }^{4}$ obstruction of these tubes can only be treated by replacement. Many conflicting opinions have been expressed on the value of Summerskill's technique..$^{2-6,9}$ According to the results of Singh and $\mathrm{Garg}^{7}$ and Jain et al., ${ }^{1}$ polyethylene intubation of the naso-lacrimal duct is a good alternative to external dacryocystorhinostomy for the cure of chronic dacryocystitis.

The only slight advantage for naso-lacrimal duct intubation may be that it requires less operative time and post-operative care than external dacryocystorhinostomy; in our view the results for this technique are so unreliable that it remains doubtful whether naso-lacrimal duct intubation in adults has a useful role at present.

\section{S. Rizzo, MD \\ L. Baldeschi, MD \\ P. Frezzotti, MD \\ C. Torrazza, MD \\ M. Nardi, MD}

Clinica Oculistica

Università degli Studi di Pisa

Via Roma 56

56126 Pisa

Italy

\section{G. E. Rose, MS, MRCP, FRCS, FRCOphth}

Moorfields Eye Hospital

London EC1V 2PD

UK

\section{References}

1. Jain SC, Srivastava SP, Saini VK. Intubation of the sac and nasolacrimal duct in chronic dacryocystitis by a specially designed polythene tube. In: Yamaguchi M, editor. Recent advances on the lacrimal system. Kyoto: XXIII International Congress of Ophthalmology, 12-13 May 1978:158-62.

2. Dejean C. Les causes d'insucces dans l'intubation lacrymale. Arch Ophthalmol 1955;15:474-8.

3. Mireki R. Lacrimal intubation from the rhinological point of view. Acta Ophthalmol (Copenh) 1966; 44:501-4.

4. Summerskill WH. Dacryocystorhinostomy by intubation. Br J Ophthalmol 1952;36:240-4.

5. Stallard HB. Eye surgery. Bristol: Wright, 1973:309.

6. Vicencio $A B$. Use of nylon thread and polyethylene tubing in naso-lacrimal duct stenosis. Arch Ophthalmol $1956 ; 55: 267-8$

7. Singh DS, Garg RS. Polyethylene intubation of the nasolacrimal duct in chronic dacryocystitis. $\mathrm{Br} \mathrm{J}$ Ophthalmol 1972;56:914-8.

8. Patrinely JR, Gigantelli JW. Dacryocystorhinostomy. In: Linberg JV, editor. Lacrimal surgery. New York: Churchill Livingstone, 1988:152.

9. Von Below H, Rose GE. Adult nasolacrimal duct bypass tubes: where do they go? $\mathrm{Br} \mathrm{J}$ Ophthalmol 1993;77:449-50. 